stantly darting with a flickering motion from the surrounding haze of similar light, and meeting in the zenith; the length of their course was as much as $15^{\circ}$ to $18^{\circ}$; they appeared to proceed indiscriminateiy from all points in azimuth.

I imnediately became aware that the whole sky, down to the very horizon, was illumined by a white, colourless aurora ; but I was so fascinated by the incessant play of the streamers overhead, that for some time I could notice nothing else. At last $I$ turned away in order to observe accurately the full extent of the arrora in all directions. I found that it reached quite down to the horizon all round; except in one place, viz., in the S.S.E. and at that point there was a symmetrical arc (of a great circle, as far as I could judge) the summit of which was about $7^{\circ}$ or $8^{\circ}$ above the horizon. This arc was perfectly well defined; within it was blue sky, and above and around, over the whole heavens, nothing but the auroral light, except in the gaps between the darting streamers in the zenith. I carefully took the bearings of this remarkable arc, and found by means of a compass the next day, that it was bisected by the magnetic meridian. The phenomena underwent no diminution during the time (an hour and a half) I was watching it. T'he sky appeared to be quite free from cloud.

I have often witnessed fine displays of aurora; one in the winter of (I think) 1848 , in this county, the colours and streamers of which were magnificent, far finer than those I saw on the 24th and $25^{\text {th }}$ of last October at Edinburgh ; but I never before observed the stars to be so much dimmed as they were at Nairn in September, notwithstanding the light on that occasion was colourless. On other occasions, I have always thought the stars quite unaffected by the auroral light, both to the naked eye and in the telescope, but on this they were obviously dimmed as by a haze.

My impression is, that no aurora that I ever saw could be visible in daylight, with the exception perhaps of this last, and the only portion of this that could possibly be seen in daylight was the well-defined arc low down in the S.S.E. I think it is just possible that in a clear and cloudless sky such an arc as this might be visible.

Stretton Rectory, Hereford, June 6 HeNRy CoOper Key

\section{$\therefore$ Red and Blue}

I WAS much interested by the letter of Mr. T. Ward (NATURE, vol. iv. p. 68) describing the appearance of a blue colour when looking at white chalk marks on a black board while the sun was shining in the eyes, as I have frequently noticed a precisely complementary phenomenon.

While walking along the chalky roads of East Kent in bright sunshine, and reading under an umbrella, I have frequently noticed that the letters appear of a deep blood-red colour ; the black colour of the type reappearing immediately on passing over the shadow of a tree on the ground, or on allowing the sun to shine directly on the book. This was so striking when first seen that I had to convince myself that the page was not printed in red ink. This is obviously the exact converse of the observation of Mr. Ward, who saw a blue colour from white marks on a black surface, while I saw a red colour from black marks on a white surface. A short time since I observed a pre. cisely similar colour when looking down on the platform of a railway station with the setting sun shining on the eyes, the cracks between the boards also appearing red, HERPERT M'LEOD

\section{Influence of Barometric Pressure on Ocean Currents}

A Low barometric pressure and an increased height of the ocean was, I believe, first assumed to stand in the relation of cause and effect by Mr. Piddington. The abnormally high tidal waves that sometimes rushed up the Hooghly during Calcutta hurricanes were ascribed to the low pressures which accompanied then. There is no doubt that unequal pressure is a true cause of currents in the ocean. But I think it, as well as difference in specific gravity, may be regarded as infinitesimal in amount, compared to the influence of the winds.

The high tidal waves at the mouth of Hooghly are not ex. perienced during the first stage of the hurricane, or so long as the wind blows from a northerly quarter. The waters in the Bay of Bengal are then propelled towards the south. It is only after the wind changes to the south and the barometer is rising that the waters are driven against its northern shores. It is when the wind happens to change to the south at the time of the flow of the ticle that great inundations occur in the Delta.

On the coast of the United States, however, there is apparently an intimate relation between low pressures and high tides. In general, so long as the barometer remains low, easterly winds are blowing on the coast and heaping up the waters in every bay. During the second stage of the storms the winds generally blow violently from the west or north-west, often at a right angle to the whole coast. These high westerly gales cause very low tides along the United States when the barometer is rapidly rising. But low tides are not experienced with high pressures if the air is calm.

High tides only occur on the coast of Europe after westerly winds have been blowing for some days in the Allantic. It is a well-recognised fact among the fishermen on the east coast of Scotland that high tides are due to this cause. I think Hugh Miller was right in maintaining that the friction of the south-west winds on the wide surface of the Atlantic must be quite as powerful in maintaining the flow of the stream through the Florida Chamel as the action of the Trade winds in forcing the tropical waters into the Gulf of Mexico.

Owing to the great rapidity with which barometric disturbances are propagated in our temperate latitudes, it is difficult to conceive how barometric pressure of itself can have an appreciable influence on the currents of the ocean. The rate of their propa gation in winter is from thirty to sixty miles an hour. In the fourth number of the "Board of Trade Weather Report" an instance is given, in which the rate is affirmed to be upwards of seventy miles an hour. The velocity in this case, however, as I may try to show on another occasion, is estimated about ten miles an hour too high. But let us suppose that no winds accompanied these rapidly propagated depressions and elevations of the barometer. A difference of an inch of pressure existing between places on the ocean two or three hundred miles apart would create only a very slow moving current, even though the diminished area of pressure were stationary. But these low pressures pass so rapidly onwards that the vis intertige of the waters of the ocean would hardly be overcome before they were again subjected to the opposite influence of an increase of pressure.

The effect of barometric pressure on the level of inland seas, like the Baltic and Mediterranean, must be still less than in the open ocean. Winds are often localised, but great depressions of the barometer extend over immense areas; in most cases far larger than the area of the Baltic. Any higher level from this cause would be brought about by the flow of the waters from either end, as the pressure might be assumed to be the same $\mathrm{n}$ both sides of that narrow sea. The mere effect of changes of barometric pressure, it will be admitted, would be quite inappreciable in any inland lake in Britain. But any one who is in the practice of fishing in the smallest of our lakes may always observe that there is an under current or "drag" created when the wind blows strongly towards the shore, in consequence of the accumulation there of its waters. The Niagara is sometimes suddenly raised two feet by strong west winds blowing over lake Erie. It is long since $\mathrm{M}$. Volney, as regards the Mediterranean, stated that east winds caused a rise or flood of from two to three feet in the harbour of Marseilles, and that westerly winds produced opposite effects. It was by a careful deduction of effects produced on a small scale that this acute observer was enabled to give a consistent outline of the causes which produced the ocean currents in general. The currents of the ocean may be regarded as coinciding very closely with the average force and direction of the winds over its surface. Since, however, Humboldt assures us that the surface water of the Gulf Stream in the Florida Straits is sometimes reversed by the force of the winter "northers," it does seem vain to attempt to trace permanent surface currents in any part of the North Atlantic, vexed as its surface is by winds so inconstant in their force and direction.

Pilmuir, Leven, Fifeshire

R. RUSSELL

\section{St. Miary's Loch, Selkirkshire}

To the student of Nature it may seem easy to decide whether the water of any given lake is good for domestic uses. But as regards St. Mary's Loch, where the question has to be settled by dint of a squabble in the Auld Reekie municipality, with all its complementary dust, smut, and heat, the true aspects of Nature are liable to misrepresentation.

Although not resident in Edinburgh, nor subject to its prejudices and ratings, your correspondent has taken considerable 